Volume 1

Issue 3 Spring 1997: Symposium - Physician-

Assisted Suicide

Article 7

November 2015

\title{
Aquinas and Morphine: Notes on Double Effect at the End of Life
}

Stephen R. Latham

Follow this and additional works at: https://via.library.depaul.edu/jhcl

\section{Recommended Citation}

Stephen R. Latham, Aquinas and Morphine: Notes on Double Effect at the End of Life, 1 DePaul J. Health Care L. 625 (1997)

Available at: https://via.library.depaul.edu/jhcl/vol1/iss3/7

This Article is brought to you for free and open access by the College of Law at Digital Commons@DePaul. It has been accepted for inclusion in DePaul Journal of Health Care Law by an authorized editor of Digital Commons@DePaul. For more information, please contact digitalservices@depaul.edu. 


\title{
AQUINAS AND MORPHINE: NOTES ON DOUBLE EFFECT AT THE END OF LIFE
}

\author{
Stephen R. Latham, J.D., Ph.D.*
}

\section{INTRODUCTION}

One strategy used by proponents of a right to physician-assisted suicide and euthanasia has been to attempt to show there is no real moral difference between physician-assisted suicide, euthanasia, and various other currentlyaccepted end-of-life medical practices. It has been argued, for example, that there is no real moral difference between a physician's withdrawal of life-support from a consenting terminal patient and providing such a patient with a lethal prescription drug. Similarly, it has been argued there is no real moral difference between a physician's relieving a patient's misery by administering a lethal dose of a prescription drug, and a physician's relieving a patient's misery by giving her enough pain-killer to end her pain, knowing that giving the required dosage risks causing her death. ${ }^{1}$ This

*Director, Ethics Division and Deputy Head, Institute of Ethics, American Medical Assaciotion. B.S., Harvard College, 1982; J.D., Harvard Law School, 1985; Ph.D. (Jurisprudence and Sccial Policy), University of Califomia, Berkeley, 1996. Opinions exprezsed in this article are the author's own, and not necessarily those of the AMA or any of its divisions.

'Much of the Second Circuit's Equal Protection argument for physician-assisted suicide in Quill v. Vacco depends upon rejecting the former distinction. Cuill v. Vacso, 80 F.31 716 (1996), rev'd 117 S. Ct. 2293 (1997). The Ninth Circuit has argued that a physician who gives a patient pain medication knowing that it may result in the patient's death beth foresees and intends that death. Compassion in Dying v. Washington, 79 F.3d 790, $823 \mathrm{n} .95$ (9th Cir. 1996) (en banc), rev'd sub nom. Washington v. Glucksberg, 117 S. Ct. 2258 (1997). Indeed, the court accuses physicians who distinguish directly-intended death from death which is an unintendst side-effect of pain medication of "sugar-coating the facts." Id. This same fcotnots characterizes the Doctrine of Double Effect as holding "that it is sometimes morally justifiable to cause evil in the pursuit of good." Id. Note that this article, unlike those cases, contrasts medication-ristingdeath with euthanasia rather than with physician-assisted suicide. In physician-assisted suicide, the patient is given a lethal amount of a drug, but is left to take or not tale it at her onn discretion. In euthanasia, as in the medication-risking-death scenario, the physicinn is the cole agent. This makes for an instructive comparison, partly because it leaves aside the question of the effect upon physician responsibility of the intervening agency of the patient in the physicianassisted suicide case. 
article concerns itself only with the latter alleged moral distinction, the legitimacy of which it defends.

Defense of this verbal distinction involves an appeal to the "doctrine of double effect" (DDE). DDE specifies conditions under which it is permissible to bring about harms as side-effects of one's intentional action which it would be impermissible to bring about intentionally. ${ }^{2}$ Various versions of DDE have been the subject of much philosophical debate and questions abound as to the types of ethical theory which call for or permit the doctrine's use, ${ }^{3}$ the proper formulation of the doctrine, ${ }^{4}$ and the soundness of the distinctions it attempts to make. ${ }^{5}$ This article must, therefore, begin by attempting to justify the use of DDE in the context of end-of-life care and by specifying the version of the doctrine upon which the subsequent argument is grounded. The article concludes by applying DDE to the case of end-of-life care.

\section{WHY INVOKE THE DOCTRINE OF DOUBLE EFFECT?}

This article proposes to defend the position that there is a meaningful moral distinction between the action of a physician who administers a lethal dose of medication to a consenting patient and of one who, with consent, administers an analgesic for the treatment of pain even at the risk of 1991).

${ }^{2}$ See Joseph Boyle, Who is Entitled to Double Effect?, 16 J. MED. \& PHL. 5, 475-76 (Oct.

${ }^{3}$ See Boyle, supra note 2; Alan Donagan, Moral Absolutism and the Double-Effect Exception: Reflections on Joseph Boyle's 'Who is Entitled to Double Effect.' 16 J. MED. \& PHII 5, 495-509 (Oct. 1991); William N. Nelson, Conceptions of Morality and the Doctrine of Double Effect, 16J. MED. \& PHIL. 5, 545-64 (Oct. 1991); E. Anscombe, Action, Intention and 'Double Effect,' 54 PROC. OF THE AM. CATH. PHL. Ass'N 12-25 (1982).

${ }^{4}$ See Donald B. Marquis, Four Versions of Double Effect, $16 \mathrm{~J}$. MED. \& 1'HIL. 5, 515-544 (Oct. 1991).

SSee H.LA. Hart, Intention and Punishment, in PUNSHMENT AND RESPONSTBLTTY: ESSAYS IN THE PhILOSOPHY OF LAw 113-135 (Oxford Univ. Press, 1968); P. Foot, The Problem of Abortion and the Doctrine of Double Effect, in VIRTUES AND VICES 19-32 (UNIV. OF CAL. PRESS, 1978); W. Quinn, Actions, Intentions and Consequences: The Doctrine of Double Effect, 18 PHIL. \& PUB. AFF. 334-351 (1989); Thomas J. Bole III, The Doctrine of Double Effect: Its Philosophical Viability, 7 Sw. PHIL. REv. 1, $91-103$ (1991); Frances M. Kamrn, The Doctrine of Double Effect: Reflections and Theoretical and Practical Issues, 16 J. MED. \& PHI. 5 57185 (Oct. 1991). 
accelerating the patient's death. The DDE will be used to articulate that distinction. That doctrine, in any of its various formulations, sets out criteria pursuant to which a harm (in this case, the patient's death) may permissibly be brought about as an unintended side-effect of an agent's voluntary action, even though it would be wrong for the agent to intend directly to bring about that harm. The question immediately arises as to why DDE is the appropriate vehicle for distinguishing between the two cases at issue. It is, after all, certainly true that not every moral theory requires anything like a special doctrine for sorting ways in which it is permissible to inflict certain harms on others from ways in which it is not permissible. Utilitarians, for example, have an all-encompassing test for determining whether a given harm can be brought about in a certain way: it can be brought about in that way just in case doing so will maximize overall utility. For similar reasons, most forms of consequentialism can do without a principle like DDE. Donagan has argued that Kantian ethics can sort between permissible and impermissible infliction of harms without resorting to a doctrine like $\mathrm{DDE}^{6}{ }^{6}$ and Nelson has made a similar point about a contractualist ethic.?

Indeed, Boyle has argued DDE has its natural home only within "absolutist" theories like that of the Catholic tradition, in which exceptionless moral norms prohibit inflicting certain kinds of harms on others. ${ }^{8}$ In the context of such a theory, DDE serves to limit the scope of the exceptionless norms in such a way as to make it humanly possible to comply with them. It is impossible for finite human beings to prevent some of their voluntary acts from bringing about prohibited harms. The consequences of our actions are not all in our control, and there are many circumstances in which any action we take will have a harmful effect. It is always possible, however, for persons to prevent themselves from bringing about such harms intentionally. DDE, by specifying the conditions under which harms can be brought about as unintended side-effects, limits the otherwise impossibly demanding scope of norms that prohibit certain kinds of harm ${ }^{9}$ Boyle concludes that any theory which does not include

${ }^{6}$ Donagan, supra note 3.

TNelson, supra note 3.

'Boyle, supra note 2.

${ }^{9}$ Id. at $486-87$. 
exceptionless norms against harming is not "entitled" to the tempering influence of DDE. ${ }^{10}$

Why, then, ground an argument for the moral difference between assisted suicide and pain-relief-risking death on a doctrine that is said to be of use only within certain absolutist ethical traditions? One possible answer is that Boyle's argument claiming only absolutist ethical theories are "entitled" to DDE is hardly conclusive. Quinn and Bole have persuasively argued that something like DDE is necessary to, and of wide application within, various ethical theories that do not include exceptionless norms. ${ }^{11}$ This debate can be left aside however, and instead we con appeal to a modified version of Boyle's argument. Suppose that, regardless of whether DDE is available and useful to non-absolutist theories of ethics, it is at least appropriate and useful in contexts that feature exceptionless norms prohibiting the infliction of certain harms. We need not suppose, with Boyle, that such exceptionless norms occur only at the level of overall ethical theory. Nearly any ethical theory -- including those which, like the various consequentialisms, do not include exceptionless norms against harming at the level of general theory -- can justify applying certain exceptionless norms to persons in particular social roles.

Consider the precepts, "Managers must never work against shareholder interests" and "Attorneys must never undermine the interests of their own clients." Such precepts can be justified by any number of moral theories. It need not be a feature of those justifying theories that they include general norms prohibiting all persons from damaging corporate business interests, or from undermining individuals' legal interests. Nonetheless, those theories can ground these precepts, which are absolutist proscriptions on the production of certain kinds of harm agents.

The specified agents face the same problem mentioned in Boyle: it is not always possible for a manager to conduct himself in such a way as to avoid harming shareholders' interests; it is not always possible for an attorney to avoid undermining clients' interests. Nevertheless, it is always possible for a manager or an attorney to avoid inflicting the proscribed harms intentionally. The criteria laid out by DDE thus allows persons in

${ }^{10} \mathrm{Id}$. at 488.

${ }^{11}$ Quinn, supra note 5; Bole, supra note 5. 
particular social roles to act consistently with what would otherwise be impossibly difficult rules against their bringing about certain role-specified harms. Under this view, it is not theories but particular agents, in particular social roles, who are "entitled" to DDE.

It remains to apply the above argument to the case at hand. Physicians have long been held to a role-specific obligation to "do no harm" to their patients. ${ }^{12}$ This is an absolutist, though agent-specific, prohibition. Unfortunately, the world is such that it is impossible for physicians to avoid certain voluntary acts which result in harm to patients. Surgery, for example, brings the harms of pain and discomfort to the patients and sometimes risks bringing about the harm of death. DDE allows physicians to sort, by reference to intention, between the ways in which they may do harm to their patients, and the ways in which they may not. This sorting makes the role-specific duty not to harm patients, if not easy, then at least possible, to live with. Accepting DDE in this context does not imply a broader commitment to absolutist moral theory, rather it implies only 3 recognition that physicians have an absolutist role-specific duty to avoid harming their patients.

One may object, however, that to begin an argument about the distinction between medication-risking-death and euthanasia, by positing a role-specific duty to avoid harming patients to order the assumption that euthanasia is wrong. Perhaps so. However, the modest goals of this article are simply to establish that there is an important moral difference between the two acts. If it is possible to use DDE in showing medication-riskingdeath is consistent with the traditionally-accepted norm against physicians' harming of their patients but that euthanasia is not, then, an important moral difference will have been demonstrated.

\section{THE SUBSTANCE OF THE DOCTRINE OF DOUBLE EFFECT}

Assuming a role-specific duty to avoid harming patients, DDE may appropriately be used to separate permissible from impermissible infliction of harms by physicians upon patients. But what exactly is DDE? Plainly,

${ }^{12}$ The Hippocratic Oath contains such an injunction. 
it is a doctrine governing acts which have at least two effects, one good and one bad. Obviously DDE will not and should not work to permit actions that have nothing but bad effects. Equally obviously, however, it is unnecessary to appeal to DDE in order to permit actions that have only good effects. So then, of which such actions does DDE permit, and according to what criteria does DDE permit them? The question is extremely complex. We can best address the answer, however, simply by setting out the criteria as articulated in one well-known article on DDE:

A person may licitly perform an action that he foresces will produce a good and a bad effect provided that four conditions are verified and exist at the same time:

(1) that the action in itself from its very object be gocrd or at least indifferent;

(2) that the good effect and not the evil effect be intenced;

(3) that the good effect not be produced by means of the evil effect; and

(4) that there be a proportionately grave reason for permitting the evil effect. ${ }^{13}$

Application of this doctrine to the case at hand may seem fairly straightforward. Suppose a physician is treating a terminal patient experiencing chronic pain. The physician's action of giving an analgesic (morphine) to the patient in order to control that patient's pain has two foreseeable effects: (1) it will reduce the patient's pain, ard (2) there is some chance that it will depress the patient's respiration enough to kill the patient. The four criteria show the action of giving the analgesic is permissible. First, it is in itself morally good to give a patient pain-relief when indicated. Second, the physician does not intend to kill the patient, but only to relieve pain. Third, the effect of relieving pain is produced directly by the analgesic, not by the patient's death. The physician, in other words, is treating the patient's pain at some risk of inducing the patient's death; she is not treating the patient's pain by inducing the death. Fourth,

${ }^{13}$ Joseph Mangan, An Historical Analysis of the Principle of Dolible Effect, 10 THEOLOGICAI STUD. 43 (1949). 
the need for a terminal patient to live his last days free from pain is sufficiently grave to risk even the potential bad effect of accelerating the already-terminal patient's death. This assertion seems especially true given that any days of life lost as a result of the pain medication could only have been lived as days-in-pain.

Euthanasia, too, has one good effect, relieving the patient's suffering, and one bad effect, causing the patient's death; yet it fails to satisfy the DDE criteria. Even apart from the question of whether the action of assisting in a suicide is good, the evil effect of death seems definitely intended. Moreover, the good effect is produced precisely by means of inducing the patient's death. In summary, according to the criteria set out by DDE, medication-risking-death is permissible, and euthanasia impermissible, in a regime which, similar to our own traditional regime, places an absolute role-specific bar upon physicians harming patients.

Delivered breathlessly, the above argument seems plausible, but closer inspection reveals some serious problems. Take criterion one, for example: the moral goodness, or indifference, of the act itself. This seems quite plain if we characterize the act as the giving of pain-relief to one in pain. But could we not as easily characterize the medicating physician's act as "risking the patient's life in order to reduce pain" and, therefore, evil? Could we not describe the euthanist's act as "ending the patient's suffering" and, therefore, good? If so, then the first criterion seems to swallow the others. The question here is, how are we to characterize acts in order to classify them as good, evil, or neutral pursuant to criterion one? Criterion two also needs considerable explanation. It is not immediately clear in what sense a person does not intend to produce effects which he can foresee will follow from his own voluntary actions. Criterion three is relatively straightforward: in one case, death is not the means by which the physician achieves relief from suffering; in the other, it is. Criterion four, however, gets us back into definitional problems by remaining vague on what exactly is a "proportionately grave reason?"

We are then faced, with three questions:

(1) How are acts to be specified under criterion one?;

(2) How are we to determine what the agent "intends" under criterion two?; and, 
(3) What is the sense of the requirement of "proportionality" under criterion four?

For clarification on each of these questions, we may profitably turn to the original source of the DDE -- the Summa Theologiae of Thomas Aquinas. ${ }^{14}$

DDE is generally thought to have its origins in the following passage, in which Aquinas answers the question, "Is it permissible to kill in selfdefense?"15

One act may have two effects only one of which is intended and the other outside of our intention. Moral acts are classified on the basis of what is intended, not on what happens outside of our intention since that is incidental to it, as explained above. The action of defending oneself may produce two effects -- one, saving one's life, and the other, killing the attacker. Now an action of this kind intended to save one's own life cannot be characterized as illicit since it is natural for anyone to maintain himself in existence if $\mathrm{h}$ : can. An act that is prompted by a good intention can become illicit if it is not proportionate to the end intended. This is why it is not allowed to use more force than necessary to defend one's life .... It is not required for salvation that a man not carry out actions of proportionate self-defense in order to avoid killing another person, for a man is more obliged to provide for his own life than for that of another. However because killing is only allowed by action of public authority for the common good, it is not lawful for someone who is acting in self-defense to intend to kill another man ... . ${ }^{16}$

${ }^{14}$ Thomas AQuinas, Summa Theologiae.

${ }^{15}$ For this passage from Aquinas as the locus classicus of the doctrine of double effect, sce Warren Quinn, Actions, Intentions, and Consequences: The Doctrine of Double Effect, MORALITY AND ACTION, 175 n. 3 (CAMBRIDGE UNIV. PRESS, 1993); see also ("This is tho classical statement of "the principle of double effect.") Paul Ramsey, WAR AND THE CHRISTIAN CONSCIENCE: HOW SHALl MODERN WAR BE CONDUCTED JUSTLY? (DUKE UNIV. PRESS, 1961), quoted in Sigmund, infra note 16, at 226.]

${ }^{16}$ Aquinas, Summa Theologiae, II-I, Quest. 64, Art. 7, in Paul E. Sigmund, ST. ThOMAS AQUNAS ON POLITICS AND ETHICS, 70-71 (Paul E. Sigmund ed. \& trars., WW Notron \& Co. 1988) (emphasis added). 
Naturally enough, the bulk of the passage deals particularly with the question at hand, the permissibility of killing in self-defense. However, the remaining italicized portions of the passage contain the general principles applied by Aquinas in order to answer that question. These general principles involve the proper technique for classifying and making moral evaluations of single acts, and contained within are the seeds of the four criteria examined above. But these general principles are not announced for the first time in this section of the Summa Theologiae. Aquinas himself states that they have been "explained above." Indeed, by this point in the text, the principles have been explained repeatedly, most importantly in that portion of the Summa known as the Treatise on Human Acts. ${ }^{17}$ The Treatise on Human Acts discusses those acts which are distinctively human, as opposed to those shared with lower animals, such as growth and eating to assuage hunger. ${ }^{18}$ According to Aquinas, it is the ability to initiate action in one's "will," rather than in response to external impulse, which is distinctively human. Distinctively human acts are those which are voluntary, those which are the product of the Will, or voluntas. ${ }^{19}$ Only such voluntary actions are subject to moral evaluation, because it is only for such actions that humans are responsible as agents. Actions marred by lack of knowledge are not voluntary. For instance, if a man thought a glass of liquid was water, but it was actually turpentine, and the man drank it, nonetheless, he would have voluntarily drank, but not voluntarily drank turpentine. ${ }^{20}$ Also, no action is voluntary if it is physically coerced. ${ }^{21}$ The Treatise on Human Acts, therefore, discusses those acts which are subject to moral evaluation in virtue of being voluntary, knowing and free. It is that Treatise, and not the more commonly-cited passage on self-defense, to which we must turn in order to obtain clarity with regard to our three questions about the criteria of DDE.

${ }^{17}$ The translation of the Treatise on Human Acts being used is that of John A Oestcrle in Aquinas, Treatise on Happiness (Notre Dame, IN: Univ. of Notre Dame Press, 1983). The TREATISE ON HURIAN ACTS comprises Questions VI-XXI of I-II of the SunR, IA Theocogine. [All citations hereafter will be to Question number (in Roman numerals) and Article numbers (in Arabic numerals).

${ }^{15} \mathrm{VI}$, introduction.

${ }^{19}$ VI, 2-3.

ज्ञा, 8.

${ }^{21} \mathrm{VI}, 5$. 


\section{The Specification of Human Acts}

Our first question is, how are we to specify acts for purposes of characterizing them as good, indifferent, or evil under DDE's criterion one? It will be useful to follow Aquinas in dividing all actions into interior acts of the Will, those which, like "hoping to win the lottery," occur in the mind alone, and external acts, those which, like "opening a can of beans," have an objective existence in the world. ${ }^{22}$ In general, human acts, whether interior or external, can be specified as good or evil according to the objects at which they aim. Literally, they receive their species, or their moral kind, from their objects. Thus, the phrasing of DDE criterion one: a permissible act must be good "in itself from its very object," still begs the question of what is "an object?"

The object of an action is that which the agent sets out to do or effect. Put another way, the object of an action is the good toward which the agent aims. ${ }^{23}$ After all, no one sets out to do or effect anything, except insofar as they think it good, though they may be mistaken about the matter. ${ }^{24}$

The object of an external act is not the same as its end. The object is that which one sets out to do, and the end is some further goal to which the doing is referred. ${ }^{25}$ Thus a soldier's object may be to fire his weapon into the advancing enemy lines; his end, or that to which his action of firing is referred, may be survival, or victory. In interior acts, however, the object is the same as the end. A person's idle wish that she might win the lottery is ordered or referred to nothing beyond itself. The person sets out only to wish for its own sake; and, thus, object and end are one. This changes when the person finally decides to undertake an external act aimed at

2XVIII deals with the goodness or malice of human acts in general; XIX with the goodness or malice of interior acts; and XX with that of extemal human acts.

${ }^{2} I d$. For helpful discussions on the object of a human act, see RALPH MCINIRNY, AQUINAS ON HuMAN ACTION: A THEORY OF PRACTICE 80-82 (Cath. Univ. of Am. Prisss, 1992); ST. ThOMAS AQUINAS, SUMma THEOLOGIAE, APPENDIX 11 and in Appendix 11, "Moral Objectives," to Thomas Gilby, OP, trans., (Cambridge: Blackfriars, 1963), vol. 18, at 158-71; see THE CATEChism of THE CATHolic ChuRCh, PART III, ART. 4, 485-87 (Doubleday, 1995).

${ }^{24} \mathrm{XIX}, 1$.

${ }^{25} \mathrm{XVIII}, 4,6,7$; see McInerny, supra note 23 , at 82 . 
winning the lottery. The moment she sets out to buy a ticket, object (the buying of the ticket) and end (winning the lottery) are again separate. ${ }^{25}$

External human acts, then, are initially specified by, or receive their kind from their objects. We use our reason to judge acts of that kind either good or evil. This judgment naturally involves our consideration of the effects of acts of that kind. After all, the object of any act is defined by the effects it produces. The object of an act of theft is the acquisition of another's property, and, indeed, an act cannot be an act of theft unless one of its effects is the deprivation by the thief of another's property. This effect being an evil, the act in question is evil in its species. But this is not to say acts are good or evil according to the consequences they produce.

Suppose I am holding a briefcase which, unbeknownst to me, contains a ticking bomb. The thief who steals this briefcase from me and then hides it in a dumpster, intending to return to it later, has done an act which has excellent effects. Nonetheless the act is an act of theft, and as such, is evil. The distinction must be drawn between effects which are per se parts of acts, or which generally accompany acts of that kind, and effects which accompany acts only incidentally. Our judgment about the good or evil of a species of act depends upon the general or per se effects of that species of act and not upon results in particular cases. ${ }^{27}$ Particular acts of theft can have good effects, as particular acts of truth-telling can have bad effects. But those acts receive their species from their objects, and are judged good or evil according to their species, rather than according to their results in particular cases. "A consequence does not make an act which was good evil, nor an act which was evil good."23

Suppose though, that the thief stole bread in order to feed his family. The object of his act is still the conversion of another's property. To claim that his act was morally good is to confuse end, or the further goal toward which the thief's doing was ordered, with object, or that which the thief's act was meant to effect. An evil act, an act with an inappropriate object,

${ }^{2}$ This is a very cursory summary of the doctrine. For example, Aquinss discusses at length the possibility that single actions may be ordered to multiple ends, and that ends may be hierarchically organized. XII, 1, 2, 3 .

${ }^{27 X X}, 5$; see McInemy, supra note 23, at 80-\$3.

${ }^{2} \mathrm{XX}, 5$. 
cannot be excused because of the further end toward which it is ordered. ${ }^{29}$ In simpler words, the end does not justify the means.

There remains, however, one further complication: an act with an appropriate object, an act good in its species, can be ordered toward an inappropriate end. Suppose I give to charity. The object of my act is the transfer of my wealth to the poor, yet the end toward which my act is ordered might be vainglory, the desire for a reputation as a pious and kind man. Judged externally and according to its object, my act is a good one. However, the inappropriateness of my end in doing the act renders it evil. ${ }^{30}$

Our first question was, how are we to specify acts for purposes of characterizing them as good, evil or neutral? The answer from Aquinas is, simply, by attending to their objects. Essentially, what does the agent set out to do? In the case at hand, one agent sets out to give morphine to a patient, and the other sets out to kill a patient. Both actions are ordered to the further good end of relieving the patient's suffering, however, only the first is good or neutral "in itself from its very object."

\section{What do the physicians intend? \\ (What is intention?)}

Our second question is, how are we to determine what the two agents in our case intend? This requires us to understand the meaning of the term "intention" as used in DDE. Once again, clarity can be obtaired by looking to the Treatise on Human Acts.

In the Treatise, Aquinas offers an elaborate account: of the steps involved in taking any human act. ${ }^{31}$ Every human act may be conceived of as having been brought about through a series of interrelated actions of the intellect and the will, both faculties of the mind. ${ }^{32}$ The functions of intellect include the ability to understand facts about the world, and to reason and make judgments about them. Will is responsible for setting in motion, or

${ }^{20}$ XVIII, 7.

${ }^{30 X V I I I, ~} 4,6,7$.

${ }^{31}$ The following section summarizes X-XVII. Aquinas' ordering here is particularly difficult. For helpful expositions, see "Structure of a Human Act," Appendix 1 to Gilby, supra note 23, vol. 17, at 211-17; VeRNON J. BOURKE, Aquinas, in ETHICS IN THE HiSTORY OF WESTERN PHILOSOPHY, 103-109.

32In what follows, "Will" with a capital W denotes the human faculty, and "willing" the activity undertaken by it -- thus, the Will wills. 
"willing" the actions necessary to pursue that which the intellect finds desirable.

Every human act begins when the Intellect seizes upon some end, some state of the world toward which subsequent action could be directed. Say, for example, that a student's Intellect lights upon the idea of "understanding the philosophy of Aquinas." In response to that moment of the Intellect, her will then wishes, as idly as it were, for attainment of this end. She wishes, in other words, for the state of the world in which she understands Aquinas. That may seem to be the end of the matter, however, we often wish things were so, and never begin to think about how they could become so, or how we could make them so.

But suppose, next, that her Intellect determines that this end is actually attainable. Her Will then begins to intend (in-tentio, tend toward) this end more actively. "Intention," then, is the leaning of the Will toward some end, the resolve to attain it.

Merely to intend an end is not yet the same thing as to elect a specific means toward attaining that end. Our student must still deliberate about the various means for learning about Aquinas that are available to her. She may, for example, consider kidnaping a philosopher, or enrolling in a local university's night school philosophy class, or reading the Summa on her own. To what the intellect determines are the more reasonable of these means, hopefully the latter two, the Will consents as possible options. Having narrowed the options to a few, the Intellect then decides which among them seems best, in the student's case, reading the Summa. The Will, in turn, elects (electio) this means. At some appropriate subsequent point, the Intellect ordains that various external actions be undertaken to pursue this means; and the Will sets the body in motion to execute these actions. Thus, the student goes to the bookstore, obtains a copy of the Summa, and begins to read. At some point in the course of her reading, the student's Intellect perceives the suitability of her actions, and her Will enjoys satisfaction in the student's accomplishment. In connection with any given action, some or all of these reciprocal actions may occur in the blink of an eye. Our student need not experience each moment consciously. Nonetheless, it is important, and somewhat daunting, to realize that a 
voluntary act may go morally wrong at any of the above moments of the will: wishing, intending, consenting, electing, executing, os: enjoying. ${ }^{33}$

We may return now to our second question: how do we determine what the two physicians in our case intend? Intention, on the above complex view of the elements of human action, refers to the Will's resolve to attain a certain end. That intention, properly speaking, is a separate movement of the Will from those which involve the selection of means. One who intends an end certainly intends achieving it by some means, but we can intend an end without yet having determined the particular means we will use to attain it. Therefore, it would seem both the euthanist and the pain-medicating physician intend only to end their patient's suffering. The difference between them seems to lie not in ends intended, but in means elected. The pain-medicating physician chooses the means of administering morphine; the euthanist the means of killing his patient.

But this is too swift a conclusion, for one can intend not only ultimate ends, but also intermediate ends. ${ }^{34}$ For example, if we suppose our two physicians' desires to end their patients' suffering are in turn ordered to another end (...the end of being a good physician), we would not then wish to say that our euthanist and our pain-medicating physician do not actually intend to end their patient's suffering, but only to be good physicians. We

${ }^{3}$ Immorality can enter at the level of willing improper ends, whether idly or actively. The sister who wishes her younger brother dead has villed an impermissible end even if she never forms any intention to pursue that end; a jilted lover who intends to get revenge upon his former girlfriend does wrong even if he is simply "biding his time" and has not yet gotten to the point of deliberating about means of achieving his intended revenge. Note that otherwise permissible external acts can be immoral if they are undertaken for an impermissible end, as, for example, when a hypocrite attends church simply to gain a reputation for piety. Avts in pursuit of permissible ends can go awry at any of the levels of choosing and executing means. Think, for example, of the politician who wishes to ensure his election. There is nothing impermissible about this end. But suppose that in his Intellect he considers, and in his Will ho consents to, means which include running an efficient campaign, doing good works for his constituents, and, if all else fails, stuffing the ballot boxes. He has done wrong even if the campaign goes without a hitch and the drastic measure is uncalled for. (That improper act of consent is undetectablo does not excuse or eliminate it.) More frequently, persons advance beycnd the stage of consenting to immoral means, and actually elect immoral means for obtaining legitimate ends. Examples here are easy to imagine. An otherwise moral act can even go wreng at the purely physical level of execution, as, for example, when one uses to much force in an athletic competition. Finally, one can enjoy even the fruits of an appropriate action inappropriately, as when a victor gloats.

${ }^{34}$ XII, 3. 
would say, instead, that they intend the ending of suffering as an intermediate or proximate end toward the ultimate and more distant end of being good physicians. ${ }^{35}$

Having said this, however, we must pause to look back and see whether any other intermediate intentions intervene before the posited end of ending a patient's suffering. Indeed, in the case of the euthanist, an intermediate intention does intervene. The euthanist has an intermediate or proximate intention to kill his patient. The swift argument above, which made the euthanist's intention seem to be the same as the pain-medicating physician's, depended upon a mischaracterization of "killing the patient" as a mere means. But it is not a means. The means of the euthanist, properly speaking, is his injecting into his patient the lethal drug. The killing of the patient is his proximate end, ordered to the more distant end of ending the patient's suffering and, in turn, ordered to the ultimate end of being a good physician.

Our conclusion must be that the pain-medicating physician intends the proximate end of ending his patient's suffering, while the euthanist intends the proximate end of killing his patient. That proximate end is ordered toward the more distant end of relieving his patient's suffering.

\section{The Requirement of Proportionality}

Our third question involves determining the sense to be given to the requirement that there be "a proportionately grave reason for permitting the evil effect." Clearly this requirement often involves a balancing of effects. Thus, Frances Kamm substitutes this requirement for a requirement that "the good we seek to achieve [be] greater than [the] bad."25 The New Catholic Encyclopedia substitutes a requirement that "the good effect [be] sufficiently desirable to compensate for the bad effect."37 But we must be careful to notice this balancing of effects is not the same as the balancing associated with certain brands of consequentialism. Good effects, even large good effects, cannot make acts which are bad in their species into good acts. This balancing of good and evil effects occurs only after the

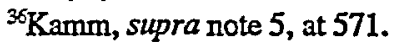

${ }^{37} 4$ NEw CATHOLIC ENCYCLOPEDIA 1020-22 (MCGraw-Hill, 1967). 
requisite hurdle of intentionality has been cleared, and only after it has been determined that the act intended is, in itself, good or neutral.

As stated above, in any act which could be permitted by DDE, the bad effect cannot be the object of the action or the end of the action. Where the object of the action is evil, criterion one is violated; where the end intended is evil, criterion two is violated. Such bad effects that are to be tolerated must, instead, follow as consequences of the means we are forced to choose. The question whether there is a sufficiently grave reason to allow the evil effects must, therefore, translate into a question whether the means we choose, or the means that give rise to unintended, but foreseeable evil effects, are the appropriate means for achieving the desired end. Whether this is so depends upon consideration of the circumstances of the action.

"Circumstances" here is a term of art, inherited by Aquinas from Aristotle and Cicero, referring to all the various questions -.. Who? What? Where? By what aids? How? When? -- which we might use to individuate an action which is only generally specified by its object. ${ }^{38}$ To be good, an act must have a good object, a good end, and good circumstances. An otherwise good act, according to Aquina's discussion of self-defense, "can become illicit if it is not proportionate to the end intended.".39 This proper proportion depends upon the circumstances of the act, the actual how and when and by-what-aids of it. Thus, to give to charity is a good act, but not if one gives to charity at a time when one has barely enough resources to tend to the needs of one's children. To give another example, the external act of swatting a mosquito on one's child's arm is permissible, but to do so using a brick introduces a circumstance, by which aids [means], makes the act evil. ${ }^{40}$ Evaluation of circumstances is thus a kind of consequentialist evaluation; though, to repeat, a kind which begins only after the action in question has been characterized as to moral species. The question referred to inconsequential analysis is whether this particular act is an appropriate one of its species.

${ }^{38}$ VII, 3; XVIII, 3, 10, 11.

${ }^{39}$ Aquinas, supra note 16.

${ }^{40}$ The classical list of circumstances also included the question "Why." Aquinas dutifully lists "Why" along with the other questions about circumstances, but, because it inquires about internal ends rather than external circumstances, gives it special treatment. Sce VII, 4. 
The question for our pain-medicating physician is whether the circumstances are such that it is appropriate, in the particular case before him, to achieve his end of eliminating his patient's suffering by using means which risk the bad effect of killing his patient. In many cases, the answer will be yes. But there are cases, the case, for example, of a young burn victim who will likely survive his very painful injuries, in which risking a patient's death in order to achieve pain relief might not be appropriate. The question for the euthanist would, had the euthanist been able to pass the earlier hurdles, be whether the medical circumstances justify his eliminating this particular patient's suffering by giving him a lethal injection. If there were other means available to him to achieve his end medication, personal attention, pastoral care, withdrawal of unwanted and burdensome medical care - then it would be hard for him to make the case that there is a grave enough reason for him to bring about this patient's death.

\section{APPLICATION OF THE DOCTRINE OF DOUBLE EFFECT}

We have, at long last, completed our inquiry into the substance of the doctrine of double effect. It remains only to apply the doctrine, now thoroughly understood, to the case at hand. This exercise is simply a matter of pulling together what has already been said. It can, at this point, be accomplished quite swiftly.

With regard to the euthanist: his action of giving a lethal injection to his patient has two effects; one good, the elimination of suffering, and one bad, killing the patient. Is his act, in itself from its very object, good or neutral? No, because his object is to kill his suffering patient. Does he intend only the good effect and not the bad? No, because he intends the death of his patient as a proximate end. Is the good effect of relief of suffering not to be produced by means of the evil effect of killing? No; it is precisely the killing which will produce the desired good effect. Is there a proportionately grave reason for causing the death? If there are any means available, short of killing the patient, to end the patient's suffering, then the answer is likely to be "no." In any case, the euthanist has failed to meet the criteria of DDE.

With regard to the pain-medicating physician, his action of giving morphine to his patient has two effects, one good, the elimination of 
suffering, and one bad, the risk of killing the patient. Is his act, in itself from its very object, good or neutral? Yes, because his object is to give his suffering patient morphine. Does he intend only the good effect and not the bad? Yes. Is the good effect of relief of suffering not to be produced by means of the evil effect of risking the patient's life? Yes; the relief of suffering is aimed at in spite of, not by means of, subjecting the patient to risk. Is there a proportionately grave reason for permitting the death? Here, the answer depends upon the circumstances of the case. If, for example, there are means available to end the patient's suffering that would not involve risking his life, then the answer must be "no." But if no such alternative means are available, and the other circumstances are appropriate, then the pain-medicating physician has solicited all of the DDE criteria.

In medicine, as it has been constituted for centuries, physicians have a role-specific obligation not to harm their patients. ${ }^{41}$ This obligation is impossible to fulfill unless it is limited by prohibiting the intentional causing of harms. DDE spells out criteria for determining which harms are caused intentionally and are therefore prohibited. Medicating a patient for pain even to the point of risking that patient's death satisfies the criteria of DDE. Euthanizing a patient in order to end his suffering does not. It follows that there is a morally significant difference between the two acts.

\section{CONCLUDING REMARKS}

This concluding section will address two lingering problems; one concerning the sincerity of pain-medicating physicians and the other concerning the contemporary understanding of DDE as a doctrine of hard cases.

\section{The Insincere Pain-Medicator}

A suspicious reader might inquire, "How do we know what the painmedicating physician truly intends? Suppose the physician harbored a secret intention to kill his patient -- indeed, a secret intention to end his patient's suffering by killing him with morphine. Would this not change the

${ }^{41}$ See Hippocratic Oath, supra note 12. 
analysis?" Indeed it would. The pain-medicating physician would then be a euthanist in disguise. The fact that true intentions can be disguised should not change our conclusions regarding the propriety of acting according to the professed intentions, or about the impropriety of acting according to the disguised intentions. In most cases, however, we must be satisfied with the theoretical analysis because it is simply beyond our power to see into the hidden intentions of agents.

But perhaps the case of the pain-medicating physician is different. Perhaps in this case, there really is a way to verify whether the physician's professed intentions are the same as his real intentions. After all, if a physician's real intention was to kill his patient with pain medication, would he not use an over-generous dose of pain medication? Could we not check the medical records of our physician to determine whether his dosage-level was appropriately proportionate to his patient's need for pain-control?

But suppose the physician was very crafty, and, in order to disguise his real intention to kill his patient, carefully metered his doses of pain-killer to track the patient's pain-control needs. Then, at the right moment, he winkingly delivers a dose which is appropriate to the patient's pain-control needs but which risks the patient's death. And suppose he does this intending the patient's death!

If so, the physician would then be a euthanist, acting just like a painmedicating physician. It would, nonetheless, be false to claim that there was no moral difference between this euthanist and a sincere painmedicating physician.

\section{An Easy Case for a Hard Doctrine}

DDE tends to be discussed in the context of hard cases. Abortions, craniotomies, trolley-car derailings, and the bombing of civilians are the regular materials of the contemporary ethicist examining DDE. This fact tends to give discussion of the doctrine a sophistic air, however DDE is not, at heart, a doctrine for the distinction of hard cases. It is a technique for characterizing single acts as permissible or impermissible. Its utility in ordinary circumstances may be clarified by considering its application in an everyday, non-hard case.

A physician wishes to perform a medical procedure -- say, a coronary artery bypass graft (CABG). That act has two effects, one good, the curing of the patient's heart condition, and one bad, the risk that the patient will 
die on the operating table. The CABG procedure, in itself from its very object, is good. The good effect and not the evil effect is intended. The good effect is not to be produced by the evil effect. Under the appropriate medical circumstances, there will be a proportionately good reason to permit the evil effect. DDE thus vindicates the $C A B G$ procedure. This is not a hard case but, rather, is ordinary medical common sense. DDE here serves the very useful purpose of sorting permissible from impermissible medical procedures in a world in which physicians are prohibited from harming their patients, and physicians can plainly see that nearly every medical procedure entails some risk of bringing about harmful effects.

Perhaps if we begin to think of "pain control through medication" as a medical procedure like any other, the DDE analysis of the painmedicating physician's act may begin to seem more like common sense and less like sophistical fiddling with hard cases. 